\title{
Aspects Regarding the Tribological Behavior of Turcite and Relamid Polymeric Materials, in Sliding Motion Couples
}

\begin{abstract}
IVONA CAMELIA PETRE, ILEANA NICOLETA POPESCU, DAN NICOLAE UNGUREANU*
Valahia University of Targoviste, Faculty of Materials and Mechanics Engineering, Campus, 13 Aleea Sinaia, 130004, Targoviste, Romania

The application of plastic materials in various areas of contemporary technology can lead to improvements in the function, quality and performance of engineering components. When determining the field of use of these materials, it is necessary, in addition to knowing the physical and mechanical properties, information about their behavior in service under the influence of the operating and environment factors. Compared to metallic or ceramic materials, polymeric materials exhibit a wide range of scratching deformations in a narrow range of pressure, speed, temperature, lubrication etc.I In this paper is proposed a penetration model of a flat surface (from polymeric material) with a rigid conical penetrator and the determination of the flat surface material response mode. The penetration method corresponds to the deformation produced by the asperities in practice.The comparison of the experimental and the theoretical results confirms the veracity of the model and corresponds with many of the experimental results obtained in the specialized works.Based on the proposed models, maps can be produced, that can illustrate the response of any polymeric surface in contact with an abrasive material.
\end{abstract}

Keywords: Tribological behaviour, Penetration model of a flat surface, Microploughing, Inclination angle, Turcite and Relamid polymeric material.

Depending on the type of mechanical system in which materials are used (guides, bearings etc.) and the operating conditions (load, speed, temperature, running time, slip distance), differentfriction and wear processes may occur.

The diversity of materials used in the kinematic sliding couplings [1-9] and the complexity of friction and wear phenomena [10-11] make two basic types of wear adhesion and abrasion wear predominant in dry conditions.

The adhesion wear present in the operation of any friction couple is most often manifested by the transfer of polymeric material on the surface of the metal semicouplers, and its forms of manifestation are not among the most aggressive. The newly formed molecular layer can reduce the wear intensity 2...,3 of times [12-14].

Abrasion wear has more aggressive shapes due to the difference in hardness of the contact material. The surface of lower hardness material (polymeric material) can undergo irreparable changes in slip on a surface with a higher hardness (cast iron).

In these conditions, several forms of expression can occur in the contact area between the two surfaces: microchipping, tearing, coulter, scratching, fatigue etc. Various studies conducted in the literature [15-19] illustrate that polymeric materials, under the influence of external forces and working conditions, exhibit a wide range of scratching deformation characteristics.

The paper proposes a deterministic investigation model, by scratching a rigid flat surface (made of polymeric material - Turcite, Relamid) with a conical shape penetrator (from cast iron) and its experimental validation.

\section{Analytical model for calculating the wear of polymeric materials}

As it is known from the literature [20-23], the appearance of a shape or other wear depends, in particular, on the ratio of the hardness of the surfaces in contact, the surface processing mode, the contact pressure between the conjugated surfaces, the exploitation conditions etc.
Various studies illustrate the deformation of polymeric materials by penetrators of conical or pyramidal form [2, $4,13,17,22-26]$. The scratching pattern with such penetrators corresponds in practice with the deformations produced by the surface roughness. All reasoning for the two models presented can be considered as an indicator of the abrasion efficiency of the cone.

\section{The ideal rigid cone model}

It is considered a rigid cone (castiron) which slides at a constant speed on a flat, perfectly smooth and deformable surface (made of polymeric material, fig. 1).

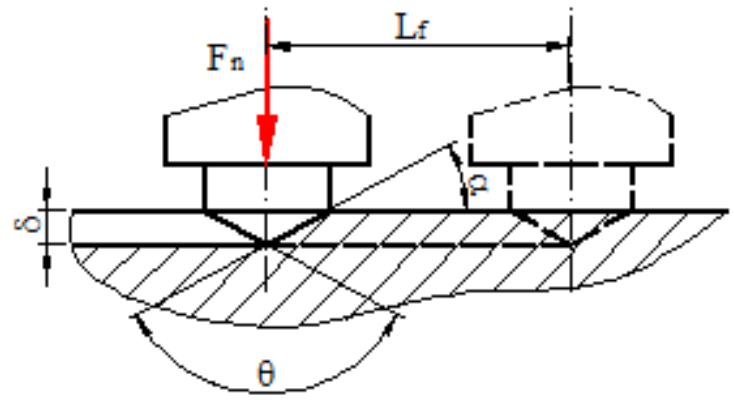

Fig. 1. Abrasion model with rigid cone

The depth of plastic penetration of the cone $(\delta)$ depends on the flow resistance of the surface material, which can be considered as the hardness $(\mathrm{H})$, the angle of inclination of the cone $(\alpha)$ and the normal force $\left(F_{n}\right)$ (the angle of the penetrator is $\theta$ ). The normal force acting on the penetrator is only supported by half of the contact:

$$
F_{n}=0,5 \cdot \pi(d \cdot \operatorname{ctg} \alpha)^{2} \cdot H
$$

In these conditions, the depth of penetration of the cone on the single pass will be:

$$
d=\left(\frac{F_{n}}{H \cdot 0,5 \cdot \pi}\right)^{1 / 2} \cdot \frac{1}{\operatorname{tg} \alpha}
$$

The ideal volume of material removed by the penetrator at a single pass over a distance is $\mathrm{L}_{\mathrm{f}}$ : 


$$
V_{u}=L_{f} \cdot d \cdot \operatorname{ctg} \alpha=\frac{2 L_{f} \cdot \operatorname{tg} \alpha}{\pi \cdot H} \cdot F_{n}
$$

If only a part $(K)$ of all abrasive contacts is considered to produce abrasive wear, then the total wear volume will be:

$$
V_{t u}=K \cdot L_{f} \cdot F_{n}
$$

where: $K$ it is considered to be a coefficient of proportionality.

The proportionality factor is considered as a wear ratio (Archard) and is a material characteristics [17, 22-24]. The values of this coefficient are always subunits, usually $10^{-3} \ldots 10^{-9}$ of the order of magnitude.

\section{The real rigid cone model}

The model takes into account the elasticity and plasticity characteristics of the polymeric material. Depending on the values of these characteristics under the action of the penetrator the material can be deformed differently (fig. 2).

The deformation forms can be: (i) in the form of curbs (in the case of tenacious, ductile materials fig. 2.a), which causes the material to flow near the penetrator; (ii) in the form of craters (in the case of fragile, brittle materials fig. 2.b), when material breaks appear near the penetrator.

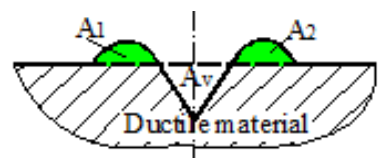

a

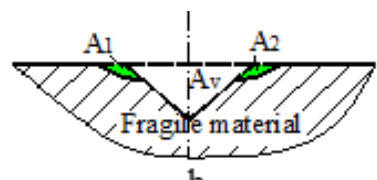

b
Fig. 2. Abrasion model according to material type $[19,20]$

The abrasion parameter $\left(f_{a b}\right)$ can be defined as the ratio between the amount of displaced material during wear and the amount of wear.

For ductile materials the abrasive parameter is:

$$
f_{a b}=1-\frac{A_{1}+A_{2}}{A_{v}}
$$

For brittle materials the abrasive parameter is of the form:

$$
f_{a b}=1+\frac{A_{1}+A_{2}}{A_{v}}
$$

where: $\left.A_{1}\right) A_{2}$ are the areas of the curved sections or craters; $A_{v}$ is the area of the cross section of the wear track.

It has been experimentally found that for tenacious materials $f_{a b}<1$ and for brittle materials, $f_{a b}>1$. The abrasivity parameter is determined according to the rheological characteristics of the deformable material.

\section{Experimental part}

\section{Selection of materials}

In the paper were analyzed two materials used in the case of sliding movement couplings, the guiding of machine tool guides, equipments, devices etc. The paper does not aim to highlight if any of the materials subjected to the analysis has better tribological properties, it examines whether these polymer materials (thermoplastics: Relamid and Turcite) are subject to the proposed abrasion models.

Used with sliding-motion couplers (guides of machine tools, devices, bearings etc.), the polymer materials (Relamid, Turcite) are used due to their performance: reduced wear even without lubrication, possibility of damping and absorption of vibrations, wear limited to corrosion, mild machining etc [3, 27-30]. The properties of Realmis and Turcite polymeric materials are presented in table 1.
Table 1

THE PROPERTIES OF REALMIS AND TURCITE POLYMERIC MATERIALS [30]

\begin{tabular}{|l|c|c|}
\hline Properties & RELAMID & TURCITE \\
\hline Hardness Vickers DPH & 90 & 80 \\
\hline Tensile strength, MPa & 62 & 75 \\
\hline The modulus of elasticity, GPa & 2.07 & 1.0 \\
\hline Density, g/cm ${ }^{3}$ & 1350 & 1210 \\
\hline Thermal conductivity, W/m/K & 0.35 & 0.17 \\
\hline Punctul de topire, ${ }^{\circ} \mathrm{C}$ & 252 & 240 \\
\hline Melting point, $\mathrm{m} / \mathrm{m} /{ }^{\circ} \mathrm{C}$ & $6.3 \cdot 10^{-5}$ & $6 \cdot 10^{-5}$ \\
\hline Specific heat, $\mathrm{J} / \mathrm{Kg} / \mathrm{K}$ & 2060 & 1860 \\
\hline
\end{tabular}

RELAMID ${ }^{\circledR}$ B-2Nf-T-(i) is a polyamide with $1 \%$ black carbon (both for improving mouldability and tribological behaviour), being treated for a better thermal stability and weather-proofing[3]. Due to its mechanical characteristics, polyamides are used for making gears, roller bearings or others various high strength parts, are used also for insulation of slot, cables, capacitors (in sheets) in the form of fabrics (for layering) paper paint [27].

The polyamide is a thermostabilized grade of PA 6 (Relamid B-2Nf-T-(i)), generally having a good UV and weather resistance - RELAMID $\AA$ additivated with a small amount of black carbon. The material could be mold in simple or complex shapes. Thermal stability makes the final product more stable, especially after thermal ageing. This property is preserved even in the presence of oxidation agents, and gives a generally better behavior compared to untreated products [28].

RELAMID ${ }^{\circledR}$ B-4G- (i) is a Polyamide 6 with normal viscosity and self-lubrication (internal lubrication) obtained by graphite additive for injection molding or extrusion. It exhibits very good physical-mechanical and chemical properties of polyamide technolimers. The graphrifiers added to the product provide the appropriate mechanical properties for incorporation into moving devices, where reduced friction coefficients are required. Compared to the self-separating polyamide assortments obtained by addition of molybdenum disulphide, the graphite variant can be used at high loading rates [29].

TURCITE ${ }^{\circledR}$ is a high performance engineered thermoplastic material, for use as plain, linear and wearring bearing elements. The characteristics of turcite are: very low friction for reduced power loss, low wear for long life, excellent chemical resistance / fluid compatibility, no stick-slip for positional accuracy / control, good specific bearing loads, unlimited shelf life, absorbs vibration during machining [31].

\section{Tribological experiments}

For the experimental part, the sliding motion pin-on-disc equipment, as schematized in figure 3 , was used.

On the rotating disk place the analyzed polymer material. In the clamping device, the cast iron conical specimens were mounted.

The friction of the samples on the test bench was made under dry sliding due to the fact that under the conditions of lubrication the plastics were soaked in oil and changed their dimensions. This is also highlighted in the paper of Rubenstein [15] which confirm that there are materials to which the grease molecules can penetrate into their amorphous areas, weakening the interfacial bonds 
between the molecules. Three conical specimens with angles $\theta_{1}=85^{\circ}, \theta_{2}=60^{\circ}, \theta_{3}=40^{\circ}, \theta_{4}=20^{\circ}, \theta_{5}=3^{\circ}$ Were used for the experiments; the defects of the conical pins were of $12 \mu \mathrm{m} /$ radius. Samples were cleaned and dried before crushing. The cast iron test specimen (350 HB hardness) was loaded with the following normal force values: $F_{n 1}=0.1 \mathrm{~N}, F_{n 2}=1 \mathrm{~N}$ and the measurements were made after $\mathrm{N}=80$ and $\mathrm{N}=180$ number of loading and rotation cycles of the plate.

The hardnesses of the two materials are: for Relamid 90 Shor $D$ and for Turcit 80 Shor D. The traces left by the penetrator on the polymeric plate were considered as wear depth.

Table 2 shows the average values of the wear depth for 3 measurements under experimental conditions after $\mathrm{N}=80$ number of cycles, and in table 3 the average values of the wear depth for 3 measurements under experimental conditions after $\mathrm{N}=160$ number of cycles.

In order to evaluate the geometry of the deformed layer, under experimental conditions, the track (groove) left by the cast iron penetrator on the test material is measured in cross-section. The wear trace geometry was measured at five points on the track circumference (located at the $r$ distance in fig. 3) and the average was made. In the

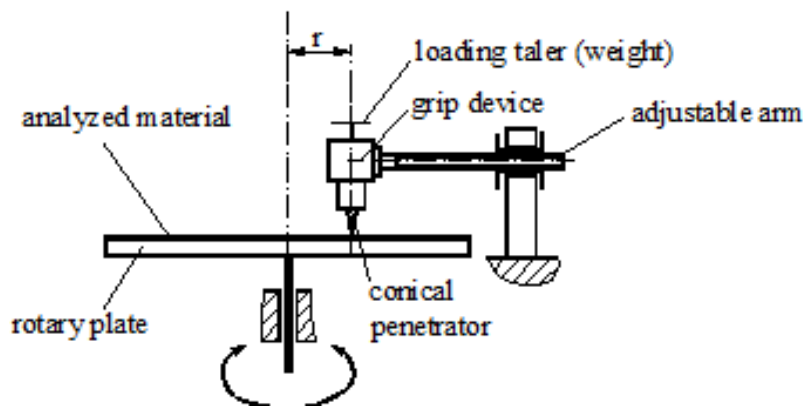

Fig. 3. Schematic presentation of the test bench, pin-on disc wear machine

transverse direction the measurements were made in 10 points.

Figure 4 shows the wear geometry for Relamid, for a force of $F_{n}=1 \mathrm{~N}$ an attack angle of $\alpha_{3}=40^{\circ}$, after $\mathrm{N}=160$ cycles. Figure 5 shows the wear pattern for Turcite material under the same experimental conditions.

For greater attack angles of $a=60^{\circ}-70^{\circ}$ and $N=160$ cycling cycles, the wear pattern exhibits other deformation characteristics, which leads us to think that the material deforms in the form of microspots, which is also confirmed in the specialized works [13,18, 20,26].

\section{Comparing the theoretical and experimental results}

Table 2

EXPERIMENTAL WEAR DEPTH FOR $N=80$ CYCLES

\begin{tabular}{|c|c|c|c|c|c|c|}
\hline \multicolumn{9}{|c|}{ Wear depth [mm] } \\
\hline \multirow{2}{*}{ Loading } & \multirow{2}{*}{ Material Type } & \multicolumn{5}{|c|}{ Angle of attack angle [ $]$} \\
\cline { 3 - 7 } & & $\alpha_{1}=10^{\circ}$ & $\alpha_{2}=20^{\circ}$ & $\alpha_{3}=40^{\circ}$ & $\alpha_{4}=60^{\circ}$ & $\alpha_{4}=80^{\circ}$ \\
\hline \multirow{2}{*}{$F_{n I}=0,1 N$} & Relamid & 0.020 & 0.042 & 0.086 & 0.098 & 0.140 \\
\cline { 3 - 7 } & Turcite & 0.022 & 0.043 & 0.089 & 0.100 & 0.142 \\
\hline \multirow{2}{*}{$F_{n 2}=1 N$} & Relamid & 0.088 & 0.094 & 0.108 & 0.124 & 0.140 \\
\cline { 2 - 7 } & Turcite & 0.092 & 0.106 & 0.120 & 0.140 & 0.156 \\
\hline
\end{tabular}

Table 3

EXPERIMENTAL WEAR DEPTH FOR $N=160$ CYCLES

\begin{tabular}{|c|c|c|c|c|c|c|}
\hline \multicolumn{7}{|c|}{ Wear depth [mm] } \\
\hline Loading & Material type & \multicolumn{5}{c|}{ Angle of attack angle [ $\left.{ }^{\circ}\right]$} \\
\hline \multirow{2}{*}{$F_{n t}=0,1 N$} & Relamid & 0.038 & 0.080 & 0.158 & 0.184 & 0.200 \\
\cline { 2 - 7 } & Turcite & 0.040 & 0.084 & 0.160 & 0.196 & 0.210 \\
\hline \multirow{2}{*}{$F_{n=2}=1 N$} & Relamid & 0.162 & 0.180 & 0.200 & 0.220 & 0.274 \\
\cline { 2 - 7 } & Turcite & 0.180 & 0.200 & 0.238 & 0.276 & 0.284 \\
\hline
\end{tabular}

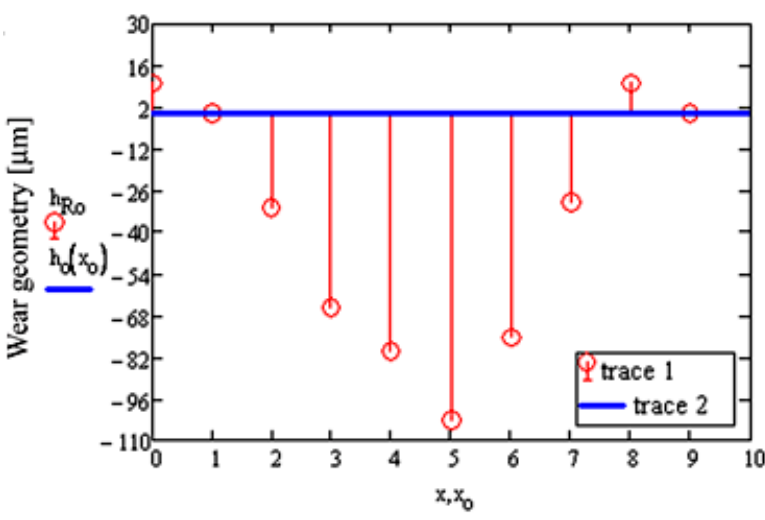

Length of palpation of the worn area [mm]

Fig. 4. Geometry evolution of the wear depth in cross-section for Relamid material

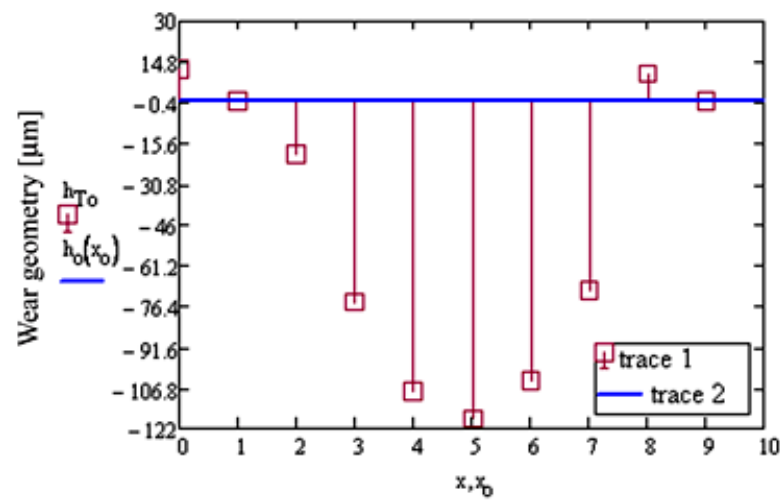

Length of palpation of the worn area [mm]

Fig. 5. Geometry evolution of the wear depth in cross-section for Turcite material 


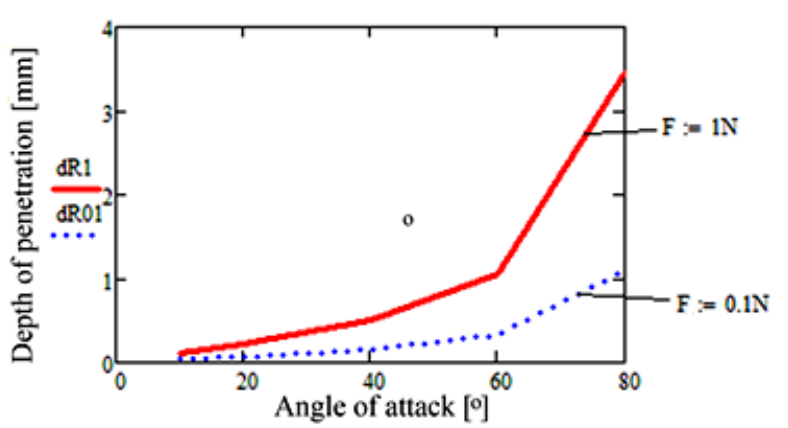

Fig. 6. Evolution of wear depth according to load and angle of attack

After analyzing of the theoretical model it consisted that the increasing of the wear depth with the load (force) and penetration angle. Figure 6 shows the evolution of the wear depth [mm] for Relamid materialdepending on the angle of attack.

It is worth noting that in the theoretical model there is an obvious increase of penetration depth at a higher angle of $60^{\circ}$.

By making a comparison between theoretical and experimental results, both trends show the tendency to increase the depth of wear with the angle of attack and loading. Figure 7 shows the wear depth for Turcit plastic material for a loading force of $F_{n 1}=0.1 \mathrm{~N}$.

\section{Conclusions}

The theoretical approach can be used to construct a series of scratch resistance maps for a range of polymers subject to different contact conditions. These maps can give information on how to deform the polymer surfaces when the scratching conditions are changed.

Because the nature of the deformation of the materials of any sliding friction couple depends on a large number of variables (pressure, velocity, shape of asperities, lubrication state, temperature, nature of materials etc.), a deterministic model is proposed in the paper, varying only the geometric parameters of penetrator and charging.

Comparing the theoretical and experimental results, there is an appreciable concordance for small values of the attack angle, especially for a small number of cycles. Inconsistencies may be due to possible measurement errors but also to the fact that in operation, in the friction between two surfaces, not only the angle of attack (given by the surface processing mode), but also other factors (sliding speed, temperature etc.) intervene.

Theoretical results are valid for a small number of load cycles. The experimental results by which the geometry of the wear line was established corresponds to many opinions found in the literature referenced in the paper.

\section{References}

1.MAJCHERCZAK D., DUFRENOY P., BERTHIER Y., Tribol. Int., 40, 5, 2007, p.834.

2.HUTCHINGS I., SHIPWAY P., Tribology: Friction and Wear of Engineering Materials, Ed. Elsevier, 2017, p. 174.

3. MAFTEI L., DELEANU L., ANDREI G., Influence of Sliding Speed and Average Pressure in Dry Regim Upon Wear of Composite with PA and Micro Glass Spheres, The Annals Of University DUNAREA DE JOS of Galaj, VIII, (XV), Issue 1, TRIBOLOGY, 2009, p.64.

4. YIGEZU B. S., JHA P. K. AND MAHAPATRA M. M., Tribol. Trans., 56, 4, 2013, p. 546.

5. POPESCU I.N., ZAMFIR S., ANGHELINA V.F., RUSANESCU C.O., International Journal of Mechanics , 4, 3, 2010, p. 43.

6.PETRE I.C., POPESCU I.N., The Phenomenological Analysis of the Nature of the Friction, from Theoretical and Experimental Point of View of $\mathrm{Al}_{-} \mathrm{Al}_{2} \mathrm{O}_{3}$-Graphite Composite /Cast Iron Pin On Disc" Sliding 58

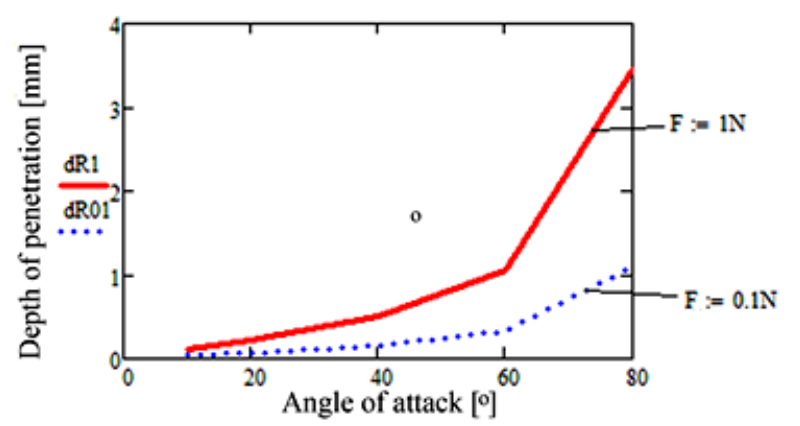

Fig.7. Evolution of the theoretical and experimental wearing trace for Turcite material

System, International J ournal of Mechatronics and Applied Mechanics, 2, 2017, p. 40.

7. POPESCU I.N., TOMA L.G., VIDU R., Composite Materials with Complex Compositions used in Vehicle Brake System: a Review, The 39th ARA Proceedingss, Frascati, Roma, DOI 10.14510/39ARA2015.3913, 2015, p.58.

8. RUSANESCU C.O. , JINESCU C., RUSANESCU M., ENESCU M.C., ANGHELINA F.V., STOIAN E.V., DESPA V., Mat. Plast., 54, 3 , 2017, p.409. 9. DESPA V., ANGHELINA F.V., IANCU D., RUSANESCU C.O., J ournal of Science and Arts, 4, 2017, p.839.

10. PETRE I., Wear Model of Sliding Motion Flat Surfaces Used in Mechanical Engineering, Applied Mechanics and Materials, 658, 2014, p. 345.

11.PETRE I., POINESCU A.A., CATANGIU A., MIHAI S., Studies regarding the reaction method to wear braking mechanism, Scientific Bulletin of Valahia University - Materials and Mechanics, 15, 12, 2017, p. 37. 12.HOLLANDER, A.E., LANCASTER J.K., Wear, 25, 1973, p. 155.

13. BRISCOE B.J ., EVANS P.D. PELILLO E., SINHA S.K., Wear, 200, 1-2, 1996, p. 137.

14.RICHARDSON, M.O.W., Wear. 17, 2, 1971, p. 89.

15.RUBENSTEIN C., Lubrication of Polymers, J. Appl. Phys., 32,

1961, p.1445.

16.KATO S., SATO N., MATSUBAYASHI T., J. of Lubrication Tech, 94, 3, 1972, p. 234.

17.LIM S.C., ASHBY M.F., Acta Metall., 35, 1987, p. 1.

18.YANG Y., TORRANCE A.A., Wear, 196, 1-2, 1996, p. 147.

19.CHALLEN J.M., OXLEY P.L.B., HOCKENHULL B.S., Wear, 111, 3, 1986, p. 275.

20.TUDOR A., Frecarea i uzarea materialelor, Ed. BREN, Bucuresti, 2002, p. 158.

21.TUDOR A., VLASE M., Uzarea materialelor, Ed. BREN, Bucureoti, 2010, p. 232.

22.KHRUSCHOV M. M., Wear, 28, 1, 1974, p. 69.

23.KOPALINSKY E.M., OXLEY P.L.B., Wear, 190, 2, 1995, p. 145.

24.CHALLEN J.M., OXLEY P.L.B., Wear, 53, 2, 1979, p. 229.

25.TORRANCE A. A., Wear, 200, 1-2, 1996, p. 45.

26.PETRE I., Determining the functional and material properties needed for abrasive wear prediction, 7th International Conference on Advanced Concepts in Mechanical Engineering, IOP Conf. Series: Materials Science and Engineering 147, 2016, doi:10.1088/1757-899X/ 147/1/012018.

27.GAVRILA D. E., BOSTACA M., Study of the Degradation of the Composite Material Polyamide-PP, Advances in Environment, Ecosystems and Sustainable Tourism, 2013, p. 231.

28.PIRVU C., GEORGESCU C., DELEANU L., Tensile Properties For Blends Of Polybuthylene Terephthalate And Polyamide With Aramid Fibers, Academic J ournal of Manufacturing Engineering, 12, 3, 2014, p. 62.

29.*** Technical Data SheetFT 1870, RELAMID B, Polyamide 6, Synthetic Fibre Research Institute (ICEFS), Savinesti, Neamt.

30.PETRE I., Durabilitatea ㅇ precizia ghidajelor cu alunecare, Editura Macarie, ISBN 973-8135-06-00, 2000, p. 47.

31.*** https://www.tss.trelleborg.com/global/en/products_2/ tssproprietarymaterials/tss-proprietary-materials.html.

Manuscript received: 19.12 .2018

http://www revmaterialeplastice ro

MATERIALE PLASTICE $\bullet 56$ No. 1 \2019 